\title{
Slowing the onset of hypoxia increases colony forming efficiency of connective tissue progenitor cells in vitro
}

\author{
Christopher M. Heylman*, Tonya N. Caralla, Cynthia A. Boehm, Thomas E. Patterson and George F. Muschler \\ *Correspondence: cheylman@uci.edu \\ Department of Biomedical Engineering, Cleveland Clinic, United States of America.
}

\begin{abstract}
Background: Survival and colony formation by transplanted tissue derived connective tissue progenitor cells (CTPs) are thought to be important factors in the success of clinical tissue engineering strategies for bone regeneration. Transplantation of cells into defects larger than a few millimeters expose cells to a profoundly hypoxic environment. This study tested the hypothesis that delaying the onset of hypoxia will improve the survival and performance of CTPs in vitro.

Methods: To mimic declines seen in an avascular in vivo bone defect, colony forming efficiency by marrow derived nucleated cells was assessed under osteogenic conditions. Variation in the rate of oxygen decline from an oxygen tension of $21 \%$ to $0.1 \%$ oxygen was explored using an incubator with programmable active control of gas concentrations. The effect of doping cultures with defined concentrations of RBCs was also used to evaluate the potential for RBCs to serve as a natural buffer in the setting of declining oxygen levels.

Results: A delay in onset of hypoxia over 96 hours resulted in a 3-fold increase in the relative colony forming efficiency (rCFE) of CTPs as compared to an immediate onset of hypoxia. The presence of RBCs in vitro inhibited the rCFE of CTPs. Given the negative effects of RBCs, methods of RBC removal were evaluated and compared for their effectiveness of RBC removal and retention of colony forming efficiency.

Conclusions: These data suggest that conditions of hypoxia compromise colony forming efficiency in marrow derived CTPs. However, slowing the rate of decline of oxygen preserved colony forming efficiency at levels achieved in a stable normoxic (3\% $\mathrm{O}_{2}$ ) environment. These data also suggest that RBCs are detrimental to the rCFE of CTPs and that buffy coat is an effective and preferred method for removing RBCs from marrow aspirates while preserving CTPs. These findings may inform clinical strategies for CTP transplantation.

Keywords: Progenitor cell, colony forming unit, bone marrow, cellular hypoxia, red blood cells, lymphoprep, blood buffy coat, cell therapy
\end{abstract}

\section{Introduction}

Connective Tissue Progenitor Cells (CTPs) are defined as the heterogeneous population of stem and progenitor cells in native tissues that are capable of giving rise to progeny that can differentiate into one or more connective tissue phenotypes $[1,2]$. They differ from mesenchymal stem cell populations in that they are not culture expanded, and therefore are not a homogenous population. They are distinctly heterogeneous in their expression of cell surface proteins or any other unifying genetic or protein signature. CTPs only require differentiation down one connective tissue pathway rather than trilineage differentiation (as is required in the definition of MSCs), to be distinguished as a CTP. The harvest, processing, and transplantation of CTPs and their progeny are central to many therapy approaches that are designed to repair and regenerate new tissues [3]. The efficacy of these approaches is dependent upon the survival of transplanted cells.

One of the greatest threats to survival of either local or transplanted CTPs is the magnitude of hypoxia that develops in a graft site and the rate of onset of hypoxia. In any graft site more than a few millimeters in dimension, oxygen tension plummets in the first 2 days following implantation [4]. Transplanted cells and local inflammatory cells consume local oxygen at a rate that is far faster than can be supported by diffusion until the time that revascularization occurs and a system of mass transport via convection is reestablished $[\mathbf{2 , 4 , 5}$.

CTPs have relatively low prevalence in native tissues. In healthy marrow aspirate, the prevalence is approximately 1 in 20,000 nucleated cells [2]. As a result, in bone marrow grafts, marrow-derived CTPs must compete with many nonprogenitors for oxygen [6]. While many cells in marrow are extremely sensitive to conditions in which oxygen tension is reduced, CTPs may have a competitive advantage over many non-progenitors in being able to survive under conditions of low oxygen tension, and to some extent may perform better under conditions of moderate hypoxia $[7,8]$. Cell processing to reduce the number of competing non-progenitors has been proposed as one possible means of reducing the magnitude of local hypoxia and improving the survival and performance of transplanted CTPs. This paper explores the feasibility of an alternative strategy: augmenting the survival and performance of CTPs by transplanting cells in an environment in which oxygen is released slowly from a secondary source, thereby blunting the rate of decline in oxygen tension. 
The presence of erythrocytes (red blood cells or RBCs) within the site of CTP transplantation is one possible buffer that might slow the rate of onset of hypoxia. As local oxygen tension drops within an area in which RBCs are entrapped, oxygen should be released from the hemoglobin in these cells and act to buffer the rate of onset of hypoxia [9].

This study was therefore designed to address two focused aims: 1) To test the hypothesis that the presence of RBCs in the milieu will improve the colony forming efficiency and performance of CTPs exposed to a rapid onset of hypoxia in vitro, and 2) To test the hypothesis that delaying the onset of hypoxia rather than preventing hypoxia will improve the survival and performance of CTPs in vitro. Additionally, several different methods for management of a marrow aspirate were compared for their relative effectiveness in minimizing CTP loss, removing non-CTP nucleated cells, and removing RBCs.

\section{Materials and methods Experimental Overview}

A series of in vitro experiments were performed to assess the effect of variation of oxygen tension, the presence of RBCs, and changes in processing methods on the colony forming efficiency of CTPs and the in vitro performance of their progeny. Fresh heparinized marrow aspirates were collected from either the proximal humerus in canines, or the human iliac crest, using established methods, described below.

Canine Marrow: Aspiration and Buffy Coat Preparation Marrow from four canine subjects (female coon hounds, age 2 to 3 years and weight 35.0 to $40.2 \mathrm{~kg}$ ) was aspirated under general anesthesia at the time of euthanasia with Cleveland Clinic IACUC approval. A Lee-Lok needle (Lee Medical, Minneapolis, MN) was positioned percutaneously in the proximal humerus. A series of $2 \mathrm{cc}$ aspirates were taken from the hematopoietic marrow in cancellous intramedullary space of the proximal humerus, repositioning the needle between aspirations. Samples were immediately diluted and anticoagulated by mixing with $1 \mathrm{cc}$ of heparinized saline (1000 IU/ml) (APP Pharmaceuticals, LLC, Schaumburg, IL). Marrow aspirates were pooled and centrifuged at 400 $\mathrm{x} g$ for 10 minutes. The buffy coat cells were resuspended in $20 \mathrm{ml}$ a-MEM medium containing $0.3 \%$ bovine serum albumin (Sigma Aldrich, St. Louis, MO) and $2 \mathrm{U} / \mathrm{ml}$ heparin and centrifuged to again isolate a buffy coat. Peripheral blood $(25 \mathrm{cc}$ ) was also obtained by percutaneous aspiration from the jugular vein, and immediately mixed with $1 \mathrm{cc}$ of heparinized saline $(1000 \mathrm{U} / \mathrm{ml})$.

\section{Human Marrow Donors: Aspiration and Buffy Coat Preparation}

Bone marrow was aspirated from the iliac crest of 24 patients (12 female and 12 male, age 25 to 76 ) undergoing elective hip or knee arthroplasty procedures in an IRB approved protocol with informed consent. Under sterile conditions, an
11 gauge aspiration needle (Lee-Lok, Minneapolis, MN) was advanced into the intramedullary cavity of the anterior iliac crest through a $3 \mathrm{~mm}$ stab incision. Peripheral blood $(25 \mathrm{ml})$ was also aspirated from a peripheral upper extremity vein at the time of intravenous needle placement. Unless otherwise noted below, aspiration and processing methods were exactly as described above for canine samples [10].

\section{In Vitro CTP Assay}

All samples were cultured in an Ex Vivo Incubator (Biospherix, Ltd., Redfield, NY). Nucleated cells were plated at a density of $10^{6}$ cells/well in 12 well, flat bottom culture plates (Corning ${ }^{\otimes}$ Costar $^{\circledast}$, Lowell, MA) or in 2 well Lab-Tek ${ }^{\text {TM }}$ Chamber Slides $^{\text {TM }}$ (Nalge Nunc International, Rochester, NY). Osteogenic media was used comprising: a-MEM media, $10 \%$ fetal bovine serum, (Cambrex, Walkersville, MD), sodium ascorbate (50ug/ml) (Sigma Aldrich, St. Louis, MO), 1\% antibiotic/antimycotic (Gibco, Grand Island, NY), and 10-8 M dexamethasone (Sigma Aldrich, St. Louis, MO) as described in previous publications $[8,11]$. All media was pre-equilibrated to the defined oxygen tension before media changes.

\section{Image Capture and Analysis of Cells and Colonies}

Cell nuclei and alkaline phosphatase activity were detected in fluorescent images that were captured and processed as described by Powell, et al., [12]. The Colonyze ${ }^{\mathrm{TM}}$ image analysis software was used as previously described to assess the observed prevalence of CTPs [Obs $P_{C T P}$, defined as the number of CTPs per million nucleated cells plated [13], and the median number of cells per colony $[\mathbf{8}, \mathbf{1 1}, \mathbf{1 2}]$ for each condition. The colony forming efficiency of each condition was calculated by standardizing the Obs $\mathrm{P}_{\text {CTP }}$ to the Obs $\mathrm{P}_{\text {CTP }}$ of the control condition for each experiment (CFE $=\left[\mathrm{Obs} \mathrm{P}_{\mathrm{CTP}}\right.$ ] CONDITION $/\left[\mathrm{Obs} \mathrm{P}_{\text {CTP }}\right]_{\text {CONTROL }}$ ). These methods are compliant with the recently published ASTM standard method for automated colony analysis [14].

Effect of the rate of oxygen tension decline on CTP colony forming efficiency and proliferation

Cells from the buffy coat of nine human marrow samples were obtained. Samples were plated at a density of $10^{6}$ cells per Lab-Tek ${ }^{\mathrm{TM}}$ chamber $\left(4.2 \mathrm{~cm}^{2}\right.$ ) (Nalge Nunc International, Rochester, NY). Media was changed on days 2 and 3. Samples were exposed to incubator controlled oxygen tensions that declined linearly from $21 \% \mathrm{O}_{2}$ to $0.1 \% \mathrm{O}_{2}$ over varied time intervals ( 0 (immediate drop), 6, 12, 24, 48, or 96 hours) using an Ex Vivo Incubator (Biospherix, Ltd., Redfield, NY) and then remained at $0.1 \% \mathrm{O}_{2}$ (Supplement Figure S1). On Day 6, cultures were fixed with 1:1 acetone:methanol for 10 minutes and stained for nuclei with 4,6-diamidino-2-phenylindole (DAPI) (Vector Labs, Burlingame, CA) and VECTOR Red alkaline phosphatase substrate (Vector Labs, Burlingame, CA) to confirm early osteogenic differentiation of CTPs and their progeny for image analysis using Colonyze ${ }^{\mathrm{TM}}[12]$. 
Effect of co-culture with RBCs in mitigating the effect of hypoxia on CTPs

Canine marrow-derived nucleated cells were plated at a density of $10^{6}$ cells per well $\left(3.8 \mathrm{~cm}^{2}\right)$ in 12 well, flat bottom culture dishes (Corning ${ }^{\circledR}$ Costar $^{\oplus}$, Lowell, MA). Peripheral blood was centrifuged at $1000 \times \mathrm{g}$ for 5 minutes. Plasma and buffy coat fractions were removed. The lower portion of the remaining packed RBC volume was rinsed with a-MEM, centrifuged again at $1000 \times \mathrm{g}$, and the supernatant removed. RBCs were added to each culture well in transwell inserts with a pore size of 0.4 um (Millipore, Billerica, MA). RBCs were added in a volume equivalent to the approximate average adult human hematocrit ( $40 \%$ of the total medium volume) [15]. Starting from the post-processing condition in which all cells and media were equilibrated to ambient atmospheric oxygen tension (21\%), samples were placed into one of three different oxygen tension conditions: $3 \% \mathrm{O}_{2}$ (physiologic), $0.1 \% \mathrm{O}_{2}$ (hypoxic), or a "48 hr Decline" in oxygen tension (i.e., an incubator controlled linear decline from $21 \% \mathrm{O}_{2}$ to $0.1 \% \mathrm{O}_{2}$ over 48 hours, followed by a constant $0.1 \% \mathrm{O}_{2}$ ). This last condition mimics the decline in oxygen tension that has been reported in a bone defect [4]. RBCs were only added in conditions of a 48 hour decline to mimic the in vivo wound environment. A 48 hour decline also takes advantage of RBC's oxygen-dependent oxygen binding properties. RBCs are expected to slowly release oxygen at a rate proportional to the rate of the slowly declining oxygen environment. $\mathrm{CO}_{2}$ levels for all conditions were maintained at $5 \%$. A medium change on day 4 was performed in an $\mathrm{O}_{2}$ controlled workspace as appropriate at 3 or $0.1 \% \mathrm{O}_{2}$. Cultures were harvested on day 6 . Cells adherent to the bottom of the chamber were fixed in acetone:methanol $(1: 1, \mathrm{v} / \mathrm{v})$ and stained with DAPI (Vector Labs, Burlingame, CA) to detect nuclei and with VECTOR Red alkaline phosphatase substrate (Vector Labs, Burlingame, $C A$ ) to confirm early osteogenic differentiation of CTPs for analysis using Colonyze ${ }^{\mathrm{TM}}$ [12].

\section{Effect of direct contact with RBCs on CTP colony forming efficiency}

Six human samples were used. RBCs were removed from the pooled marrow samples using ammonium chloride lysis methods described below. RBCs were added back to the nucleated cell samples at concentrations of $0 \%, 50 \%$, and $100 \%$ of the RBC concentration in the initial marrow aspirate. Cells were cultured for 9 days with a medium change on day 7. Colonies consisting of eight cells or more were counted on a bright field microscope.

\section{Comparison of methods for processing a bone marrow aspirate}

Seven different methods for management of a human marrow aspirate were compared for their relative effectiveness in preserving total observed CTPs (minimizing CTP loss), removing non-CTP nucleated cells, and removing RBCs: Marrow aspirate alone, buffy coat separation, 1:1 dilution with saline, each of these first three with Lymphoprep ${ }^{\mathrm{TM}}$ separation, or ammonium chloride lysis.

\section{Ammonium Chloride Lysis}

Starting with a double buffy coat sample (3-5 ml), 0.155M $\mathrm{NH}_{4} \mathrm{Cl}$ (Fisher Scientific, Pittsburgh, PA) was added in equal volume and vortexed at 2,800 rpm for 3 min with the intention of lysing RBCs while preserving other nucleated cells, including CTPs. An equal volume of $2 X$ PBS $+5 \%$ bovine serum albumin (Sigma Aldrich, St. Louis, MO) was then added to the lysis solution and vortexed for an additional $5 \mathrm{~min}$ at 2,800 rpm to halt lysis by restoring an isotonic environment. Cells were rinsed once with PBS and resuspended in a-MEM medium containing $0.3 \%$ bovine serum albumin (Sigma Aldrich, St. Louis, MO).

The viability of the remaining nucleated cells from both the $\mathrm{NH}_{4} \mathrm{Cl}$ and buffy coat $\mathrm{RBC}$ removal techniques was confirmed to be greater than $99 \%$ based on Trypan blue exclusion. Samples were plated at $5 \times 10^{5}$ nucleated cells per $9.6 \mathrm{~cm}^{2}$ well in six-well culture plates (Costar, Cambridge, MA). Cells were cultured in osteogenic medium at $37^{\circ} \mathrm{C}, 5 \% \mathrm{CO}_{2^{\prime}}$ and $20 \% \mathrm{O}_{2}$ in a humidified incubator for 9 days with a medium change on day 7. Colonies consisting of eight cells or more were manually counted using a bright field microscope.

\section{Lymphoprep $^{\mathrm{Tm}}$ Separation}

Lymphoprep $^{\mathrm{TM}}$ is an isosmotic medium with a density of 1.077 $\mathrm{g} / \mathrm{ml}$ that allows RBCs and polymorphonuclear leukocytes to sediment through the medium while retaining mononuclear cells at the sample/medium interface [4]. Density gradient separation using Lymphoprep ${ }^{\mathrm{TM}}$ (Axis-Shield, Oslo, Norway) was evaluated using marrow from four human subjects $(\mathrm{N}=4)$. Three methods of preprocessing the starting sample were compared: whole marrow, 1:1 dilution of marrow using isotonic saline, and a buffy coat preparation. $6 \mathrm{ml}$ of each sample was layered over $3 \mathrm{ml}$ of Lymphoprep ${ }^{\mathrm{TM}}$ in a $15 \mathrm{ml}$ Falcon tube.

All three samples (whole, diluted, and buffy coated) were spun in an Allegra 6 Beckman Coulter centrifuge (Beckman Coulter, Brea, CA) at $800 \times \mathrm{g}$ for 30 minutes at room temperature. Four fractions were collected after centrifugation. The top fatty layer, the cell layer, and the red blood cell layer were each separated. In addition, the few cells remaining in the serum and Lymphoprep ${ }^{T M}$ solution layers were pooled for analysis. Each fraction was diluted with $10 \mathrm{ml}$ of media and centrifuged for 10 minutes at $229 \mathrm{xg}$ to remove the remaining Lymphoprep ${ }^{\mathrm{TM}}$ solution.

Samples from each of these 4 fractions were stained with Trypan blue (Sigma Aldrich, St. Louis, MO) for viability, placed in $0.3 \%$ acetic acid to lyse any residual RBCs, and counted with a hemocytometer. All fractions were cultured under osteogenic medium conditions at a plating density of $1,25,000$ cells per $\mathrm{cm}^{2}$ in Lab-Tek ${ }^{\mathrm{TM}}$ chamber slides $\left(4.2 \mathrm{~cm}^{2}\right.$ ) (Nalge Nunc International, Rochester, NY) with medium changes on Days 2 and 3. Day 6 cultures were fixed with 1:1 acetone:methanol 


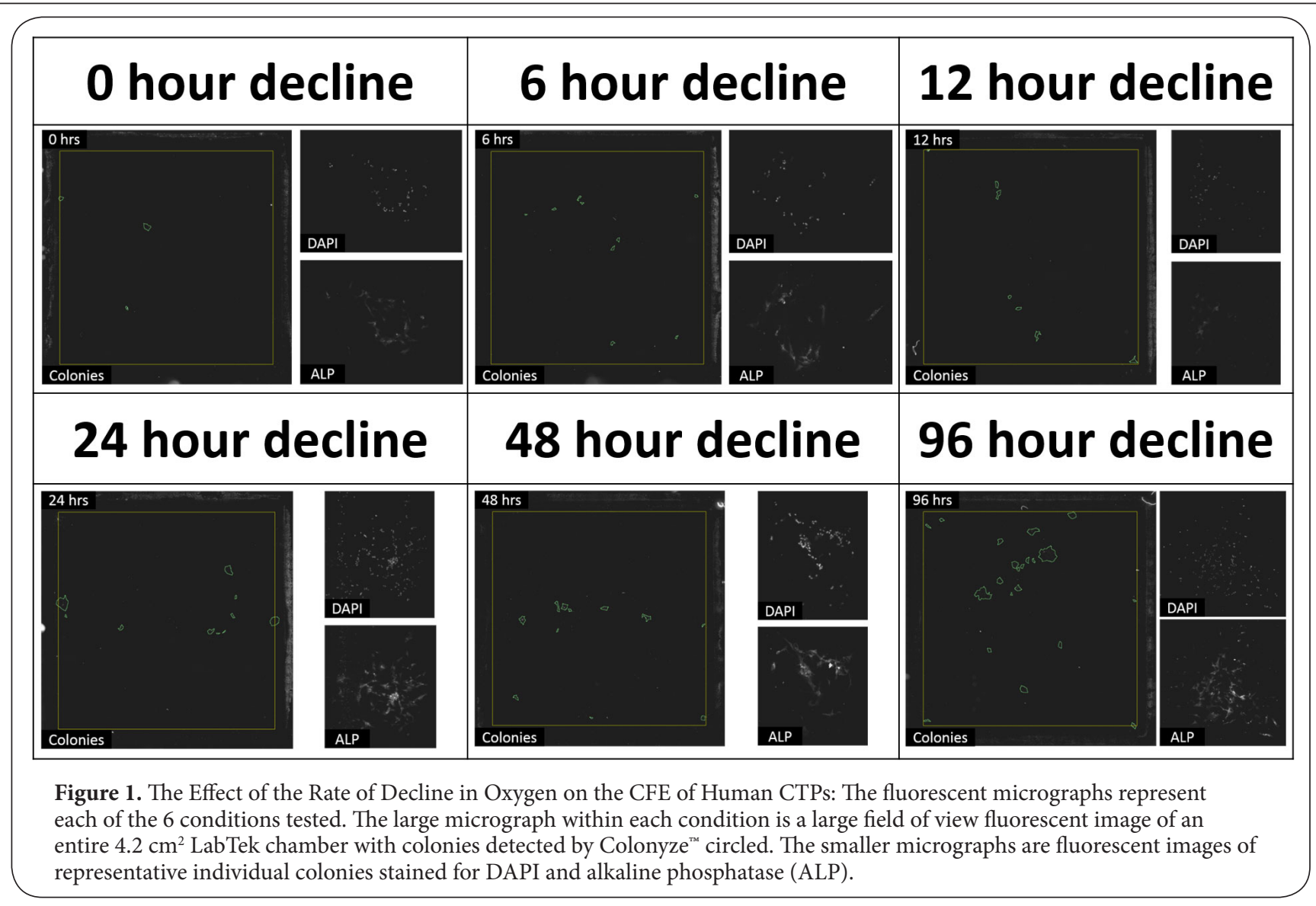

for 10 minutes and stained for nuclei (DAPI).

\section{Statistical Analysis}

All comparisons between variables were initially performed using a one-way analysis of variance with a significance of $a=0.05$. Post-hoc analysis was performed on significant variables with multiple comparisons using the Tukey-Kramer test. Error bars indicating a $95 \%$ confidence interval were reported for each standardized condition to allow for visual comparison between conditions. Lack of overlap of error bars indicates a difference between two conditions with a significance of $a=0.05$.

\section{Results}

Effect of the rate of oxygen tension decline on CTP colony forming efficiency and proliferation

Figure 1 shows micrographs of the large field of view image of an entire LabTek chamber with the colonies detected by Colonyze ${ }^{\mathrm{TM}}$ analysis. Also included are zoom images of a representative colony from each chamber stained with DAPI and alkaline phosphatase demonstrating the ability of CTPs and their progeny to proliferate and differentiate down an osteogenic pathway. Figure 2 illustrates the rCFE for samples cultured under each of the oxygen decline conditions illustrated in Supplement Figure S1. Data for each subject are standardized to the Obs $\mathrm{P}_{\text {CTP }}$ with an oxygen decline of 0 hours. A 3-fold improvement in rCFE was observed when the onset of hypoxia was delayed over 96 hours (mean rCFE : $3.0 ; 95 \% \mathrm{Cl} 1.45$, 4.57). Figure 3 illustrates that no significant change in mean cells per colony was observed for any of the conditions defined in Supplement Figure S1. The area fraction of alkaline phosphatase $\left(\mathrm{AF}_{\mathrm{ALP}}\right)$ was calculated for each condition of oxygen tension decline, where $\mathrm{AF}_{\mathrm{ALP}}=$ area (\# of pixels) of ALP fluorescence/total colony area*100. These data demonstrated no significant change in $\mathrm{AF}_{\mathrm{ALP}}$ among colonies generated under various ramp conditions. The mean $\mathrm{AF}_{\mathrm{ALP}}$ for $0,6,12,24,48$, and 96 hour declines were $0.89 \pm 4.0,0.78 \pm 3.1,0.67 \pm 2.3,0.65 \pm 3.3,1.2 \pm 4.4$, and $2.4 \pm 8.2$, $($ mean $\pm S D)$, respectively.

Effect of co-culture with RBCs in mitigating the effect of hypoxia on CTPs

Figure 4 illustrates the rCFE for samples from four subjects. The Obs $P_{\text {CTP }}$ for each subject is standardized to the Obs $P_{\text {CTP }}$ cultured under continuous $3 \% \mathrm{O}_{2}$ to obtain the rCFE. Immediate onset of hypoxia, $0.1 \% \mathrm{O}_{2}$, resulted in a $44 \%$ reduction in rCFE when compared to culture at $3 \% \mathrm{O}_{2}$ (mean rCFE: $0.56 ; 95 \% \mathrm{Cl}$ : $0.432,0.686(p=0.005))$. A delay in onset of hypoxia over 48 hours resulted in an rCFE equivalent to that at $3 \% \mathrm{O}_{2}$ (mean rCFE: $0.89 ; 95 \%$ Cl: 0.767, $1.003(p=0.399)$ ). rCFE was decreased 

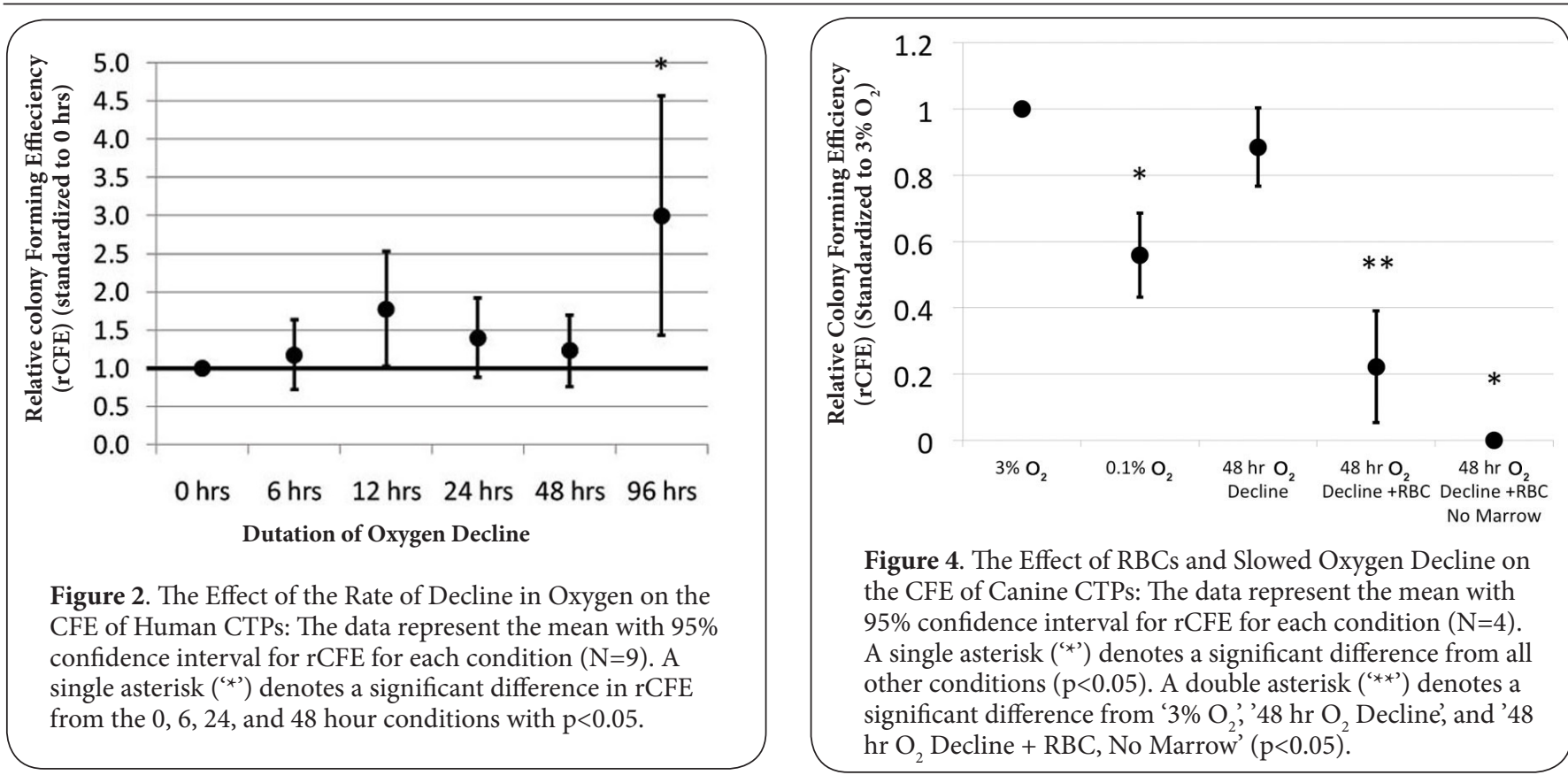

Figure 4. The Effect of RBCs and Slowed Oxygen Decline on the CFE of Canine CTPs: The data represent the mean with 95\% confidence interval for rCFE for each condition $(\mathrm{N}=4)$. A single asterisk (*') denotes a significant difference from all other conditions $(\mathrm{p}<0.05)$. A double asterisk ('**') denotes a significant difference from ' $3 \% \mathrm{O}_{2}$,' ' $48 \mathrm{hr} \mathrm{O}_{2}$ Decline', and ' 48 $\mathrm{hrO}_{2}$ Decline + RBC, No Marrow' $(\mathrm{p}<0.05)^{2}$.

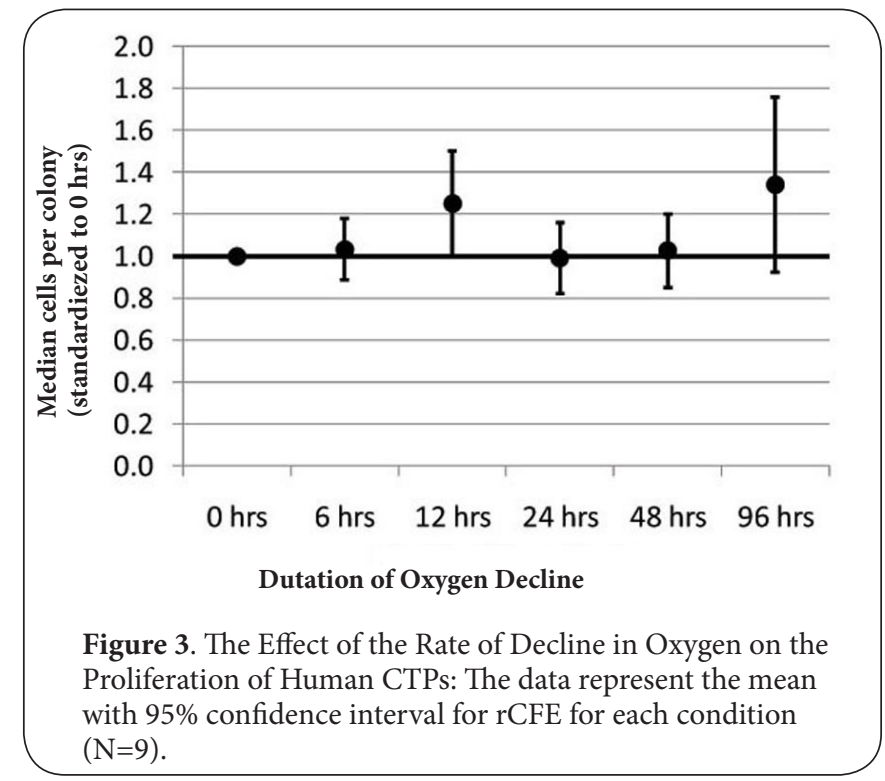

significantly when RBCs were co-cultured with CTPs despite the protection of the delayed $\mathrm{O}_{2}$ decline (mean rCFE: 0.22; $95 \%$ Cl: $0.053,0.391(p=<0.001))$. Plating only the $100 \%$ RBC aliquot without marrow confirmed that the RBC fraction from peripheral blood contains only rare CTPs.

\section{Effect of direct contact with RBCs on CTP colony forming efficiency}

Figure 5 illustrates that addition of RBCs to cultures of mononuclear cells (MNCs) decreases CFE in a dose-dependent fashion. Data for rCFE in the $50 \%$ and $100 \%$ add back groups are standardized to the MNC alone condition. rCFE was not affected by returning $50 \%$ of RBCs to the sample (mean=

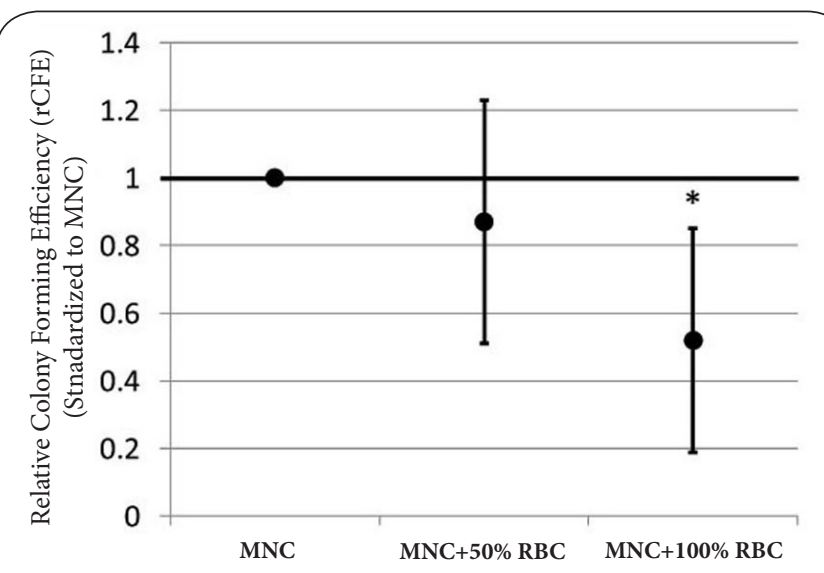

Figure 5. The Effect of Increased RBC Concentrations on the CFE of Human CTPs: The data represent the mean with $95 \%$ confidence interval for rCFE for each condition $(\mathrm{N}=6)$. Peripheral blood alone contained little to no CTPs (data not shown). A single asterisk (“') denotes a significant difference from 'MNC' $(\mathrm{p}<0.05)$.

$0.87 ; 95 \% \mathrm{Cl}: 0.511,1.229(\mathrm{p}=0.803))$. Return of RBCs to $100 \%$ of the original RBC count caused a $47 \% \%$ decrease in rCFE $($ mean $=0.53 ; 95 \% \mathrm{Cl}: 0.189,0.850(p=0.021))$.

\section{Comparison of methods for RBC Removal}

Figure 6 summarizes the effect of each RBC removal method with respect to total CTPs retained, nucleated cells retained, CTP prevalence, and efficacy of RBC removal for 4 human marrow samples. A single buffy coat caused depletion of $51 \%$ $+/-12 \%$ of total nucleated cells and $76 \%+/-10 \%$ of RBCs in the sample, but provided the best retention of CTPs ( $89 \%$ $+/-33 \%)$ from the initial sample, and also increased the Obs 


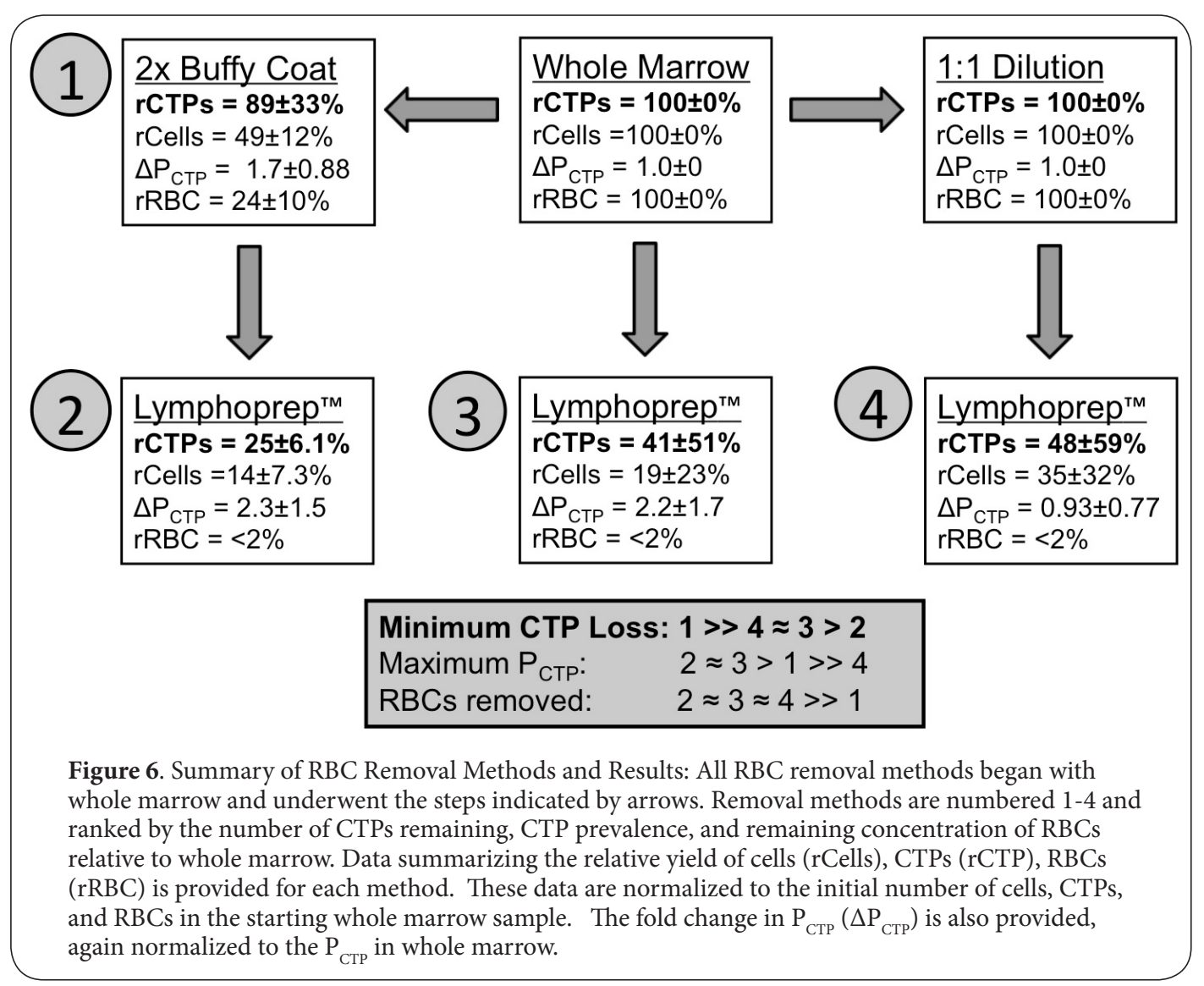

$P_{\text {CTP }}$ in the sample by 1.7 fold $+/-0.88$. Direct Lymphoprep ${ }^{\mathrm{TM}}$ processing maximally depleted RBCs $(98.5 \%+/-12 \%)$ and nucleated cells $81 \%+/-23 \%$, but only preserved $41 \%+/-51 \%$ of the CTPs in the initial sample and increased Obs $P_{\text {CTP }}$ by over two fold $(2.2+/-1.7)$. Ammonium chloride lysis resulted in the cleanest sample with the fewest remaining RBCs, but retained only $74 \%+/-34 \%$ of the CTPs. Detailed results are presented in the Supplement Figures S2, S3, S4 and S5.

\section{Discussion}

Survival and colony formation by transplanted connective tissue progenitor cells (CTPs) are important factors in the success of clinical tissue engineering strategies for bone regeneration. In defects larger than a few millimeters, CTPs are transplanted into a detrimentally hypoxic environment. This study tested the hypothesis that delaying the onset of hypoxia will improve the survival and performance of CTPs in vitro. The potential value of local red blood cells (RBCs) as a buffer of oxygen levels was also assessed.

This study was limited in scope to focus on the behavior of CTPs in an environment mimicking a bone defect. Experiments were performed in vitro using freshly harvested bone tissue and peripheral blood samples in osteogenic medium and with changing oxygen levels simulating a diffusion-limited avascular bone defect. This in vitro model does not simulate inflammatory effects, or the infiltration of tissue resident cells and their competition with transplanted CTPs for oxygen and other nutrients.

The presence of RBCs does not protect CTPs from hypoxia. These data further suggest that RBCs have a toxic effect on CTPs in vitro. Regardless of whether RBCs were added in a transwell chamber (not in direct contact with CTPS) or placed in co-culture (in direct contact with CTPs), rCFE was reduced in the presence of RBCs. The fact that reduced rCFE correlates with the mere presence of RBCs in the same medium as CTPs, and not the direct contact of RBCs and CTPs, suggests that soluble factors may contribute to this negative effect [16]. Though it is unclear which soluble factors mediate this effect, limiting the number of RBCs in a wound site may be beneficial to CTP survival and subsequent healing. There are also theoretical reasons, beyond the in vitro studies performed here, to limit RBC contamination in sites of CTP transplantation in vivo. In the setting of a fracture hematoma or a post-operative wound site, the deposition of RBCs is inevitably followed by the release of RBC contents (mostly hemoglobin) into the local tissues. This contributes to the inflammatory process and increases the subsequent influx of monocytes and macrophages, increasing local metabolic demand, and further decreasing local oxygen levels until revascularization is complete. 
CTPs exhibited increased rCFE when the linear decline of oxygen from $21 \% \mathrm{O}_{2}$ to $0.1 \% \mathrm{O}_{2}$ was slowed to occur over 96 hours. rCFE improved 3-fold ( $95 \% \mathrm{Cl}: 1.45$, 4.57) when compared to an immediate exposure to a $0.1 \% \mathrm{O}_{2}$ environment. These findings support the initial hypothesis that the survival and performance of bone marrow-derived CTPs are sensitive to the rate of onset of hypoxia. This observation raises the possibility of designing in vivo methods to delay the onset of hypoxia in clinical settings as a means of improving the survival and performance of transplanted CTPs. CFE, proliferation, migration, and differentiation of colony founding CTPs and their progeny has been shown to vary with oxygen tension $[7,8]$. Optimal colony forming efficiency has been reported in the range of 2-5\% $\mathrm{O}_{2}[\mathbf{7 , 8 , 1 7 - 2 0 ]}$. However, several investigators have demonstrated that colony formation and proliferation can still be observed at levels of $\mathrm{O}_{2}$ tension as low as $0.1 \%[7,8]$. This suggests that at least a subset of CTPs may be relatively resistant to rapid onset of hypoxia. The fact that CFE was seen to increase when the onset of hypoxia was delayed suggests that many colony founding CTPs can be recovered if sufficient time is made available for adaptation to hypoxic conditions [21]. Several authors have proposed that adaptation of bone marrow-derived stem and progenitor cells, by either brief conditioning exposure to hypoxia or a gradual onset of hypoxia, may have longerterm pro-survival effects in vivo $[\mathbf{2 2 , 2 3 ]}$. Several reports have described methods by which oxygen can be delivered into a local wound environment [24-27]. However, given the large oxygen demand of respiring cells, these methods are generally limited to the support of a relatively small number of cells for a relatively short period of time (days) [24-26]. The implication of the findings of this study is that the time required for oxygen delivery to support CTP adaptation may be on the order of only a few days. Modulation or damping of the decline of oxygen tension rather than the ongoing support of maximal metabolic demand may be sufficient to preserve a functional population of transplanted CTPs in a wound site long enough for revascularization to provide the mass transport system needed for new tissue formation.

In the RBC removal techniques presented, buffy coat proved to be most effective in preserving CTP yield $(89+/-33 \%)$. Lymphoprep $^{\mathrm{TM}}$ separation was associated with a loss of 50 $70 \%$ of the CTP colony forming activity when compared to unprocessed marrow. These findings suggest that gradient separation methods, while valuable in the preparation of "clean", RBC free samples of nucleated cell populations, may confound analysis through the inadvertent loss of CTPs. The value of RBC free samples must be balanced with the risk of CTP loss.

These data provide insight into methods that may be used to improve the sampling, processing, and assay conditions designed to measure the true prevalence of CTPs in bone marrow. Optimal assays of CTP prevalence should maximize CTP preservation and colony forming efficiency. Traditionally, the measure of the true prevalence of CTPs in bone marrow has been assayed by culture at $21 \%$ oxygen $[10,11,28-31]$. Many groups have shown that lower oxygen concentrations (1\%-7\% oxygen) yield greater survival and performance for cells taken from the marrow space $[\mathbf{1 8 , 2 1 - 2 3 , 3 2 ]}$. While rapid onset of hypoxia $\left(0.1 \% \mathrm{O}_{2}\right)$ is compatible with colony formation by some CTPs, rCFE drops by $40 \%$ when compared to $3 \% \mathrm{O}_{2}$ Based on these data, we propose that the preferred method for assay of CTP prevalence is using buffy coat isolation of nucleated cells and culture at $3 \% \mathrm{O}_{2}$.

\section{Conclusions}

In aggregate, the data presented suggest that cellular therapies using freshly isolated marrow-derived CTPs may be enhanced by defining means of delaying the rapid onset of hypoxia in the transplantation environment. These data also suggest the need for further optimization of methods to reduce RBC contamination at the site of implantation while minimizing the inadvertent loss of CTPs during cell processing steps.

\section{Additional files \\ Supplement figure S1 \\ Supplement figure $\mathbf{S 2}$ \\ Supplement figure S3 \\ Supplement figure $\mathbf{S 4}$ \\ Supplement figure S5}

Competing interests

The authors declare that they have no competing interests.

Authors' contributions

\begin{tabular}{|l|c|c|c|c|c|}
\hline Authors' contributions & CMH & TNC & CAB & TEP & GFM \\
\hline Research concept and design & $\sqrt{ }$ & $\sqrt{ }$ & $\sqrt{ }$ & $\sqrt{ }$ & $\sqrt{ }$ \\
\hline Collection and/or assembly of data & $\sqrt{ }$ & $\sqrt{ }$ & $\sqrt{ }$ & -- & $\sqrt{ }$ \\
\hline Data analysis and interpretation & $\sqrt{ }$ & $\sqrt{ }$ & $\sqrt{ }$ & $\sqrt{ }$ & $\sqrt{ }$ \\
\hline Writing the article & $\sqrt{ }$ & $\sqrt{ }$ & $\sqrt{ }$ & -- & $\sqrt{ }$ \\
\hline Critical revision of the article & $\sqrt{ }$ & $\sqrt{ }$ & $\sqrt{ }$ & -- & $\sqrt{ }$ \\
\hline Final approval of article & $\sqrt{ }$ & $\sqrt{ }$ & $\sqrt{ }$ & $\sqrt{ }$ & $\sqrt{ }$ \\
\hline Statistical analysis & $\sqrt{ }$ & $\sqrt{ }$ & - & -- & -- \\
\hline
\end{tabular}

\section{Acknowledgement}

The authors thank Richard Rozic for his technical assistance in image acquisition for Colonyze $\mathrm{T}^{\mathrm{TM}}$ analysis. The institution of the authors has received funding from NIH T32 AR050959, the Cleveland Clinic Foundation, and by the Armed Forces Institute of Regenerative Medicine (AFIRM). AFIRM is managed and funded through the US Army Medical Research and Materiel Command (MRMC). The AFIRM has additional funding from the US Navy, the Office of Naval Research, the US Air Force Office of the Surgeon General, the National Institutes of Health, the Veterans Administration, the Cleveland Clinic, and local public and private matching funds. The AFIRM contribution to this publication was supported by a subcontract from Rutgers University, Department of Chemistry and Chemical Biology / NJ Center for Biomaterials, under Cooperative Agreement No. WSIXWH-08-2-0034 from the US Department of Defense, US Army Medical Research Acquisition. 
Publication history

Editor: Kaustabh Ghosh, University of California-Riverside, USA.

Rouel S. Roque, Touro University Nevada, USA.

EIC: W. Scott Argraves, Medical University of South Carolina, USA.

Received: 01-Apr-2013 Revised: 04-Jul-2013

Accepted: 05-Sep-2013 Published: 26-Sep-2013

\section{References}

1. Muschler GF and Midura RJ. Connective tissue progenitors: practical concepts for clinical applications. Clin Orthop Relat Res. 2002; 66-80. I Article | PubMed

2. Muschler GF, Nakamoto $C$ and Griffith LG. Engineering principles of clinical cell-based tissue engineering. J Bone Joint Surg Am. 2004; 86A:1541-58. | Article | PubMed

3. Patterson TE, Kumagai K, Griffith L and Muschler GF. Cellular strategies for enhancement of fracture repair. J Bone Joint Surg Am. 2008; 90 Suppl 1:111-9. | Article | PubMed

4. Muschler GF, Raut VP, Patterson TE, Wenke JC and Hollinger JO. The design and use of animal models for translational research in bone tissue engineering and regenerative medicine. Tissue Eng Part B Rev. 2010; 16:123-45. | Article | PubMed

5. Lu C, Rollins M, Hou H, Swartz HM, Hopf H, Miclau T and Marcucio RS. Tibial fracture decreases oxygen levels at the site of injury. lowa Orthop J. 2008; 28:14-21. | PubMed Abstract | PubMed Full Text

6. Hung $C$, Nakamoto $C$ and Muschler GF. Factors affecting connective tissue progenitors and orthopaedic implications. Scand J Surg. 2006; 95:81-9. | Pdf | PubMed

7. Villarruel SM. The Effect of Oxygen Tension on the Biological Response of the Human Bone Marrow Derived Osteogenic Connective Tissue Progenitor Cell [Doctoral Dissertation, Case Western Reserve University]. 2008; 201. | Website

8. Villarruel SM, Boehm CA, Pennington M, Bryan JA, Powell KA and Muschler GF. The effect of oxygen tension on the in vitro assay of human osteoblastic connective tissue progenitor cells. J Orthop Res. 2008; 26:1390-7. | Article | PubMed

9. Jensen FB. Red blood cell pH, the Bohr effect, and other oxygenationlinked phenomena in blood $\mathrm{O}_{2}$ and $\mathrm{CO}_{2}$ transport. Acta Physiol Scand. 2004; 182:215-27. | Article | PubMed

10. Muschler GF, Boehm C, Easley K: Aspiration to obtain osteoblast progenitor cells from human bone marrow: the influence of aspiration volume. J Bone Joint Surg Am 1997, 79:1699-709. | Article | PubMed

11. Majors AK, Boehm CA, Nitto H, Midura RJ and Muschler GF. Characterization of human bone marrow stromal cells with respect to osteoblastic differentiation. J Orthop Res. 1997; 15:546-57. | Article | PubMed

12. Powell KA, Nakamoto C, Villarruel S, Boehm C and Muschler G. Quantitative image analysis of connective tissue progenitors. Anal Quant Cytol Histol. 2007; 29:112-21. | PubMed

13. Friedenstein AJ, Deriglasova UF, Kulagina NN, Panasuk AF, Rudakowa SF, Luria EA and Ruadkow IA. Precursors for fibroblasts in different populations of hematopoietic cells as detected by the in vitro colony assay method. Exp Hematol. 1974; 2:83-92. I PubMed

14. ASTM Standard F2944 - 12, 2008, "Standard Test Method for Automated Colony Forming Unit (CFU) Assays-Image Acquisition and Analysis Method for Enumerating and Characterizing Cells and Colonies in Culture", ASTM International, West Conshohocken, PA, 2003, astm.org. | Article

15. Miao G, Qingsheng Y, Zhiyuan R, Hongxian Z, Yanfang Z and Shuyan $Y$. Reference value of presenile human hematocrit and geographical factors. J Clin Lab Anal. 2002; 16:26-9. | Article | PubMed

16. Jaremko KM, Chen-Roetling J, Chen L and Regan RF. Accelerated hemolysis and neurotoxicity in neuron-glia-blood clot co-cultures. $J$ Neurochem. 2010; 114:1063-73. | Article | PubMed Abstract | PubMed Full Text

17. Adesida AB, Mulet-Sierra A and Jomha NM. Hypoxia mediated isolation and expansion enhances the chondrogenic capacity of bone marrow mesenchymal stromal cells. Stem Cell Res Ther. 2012; 3:9. | Article | PubMed Abstract | PubMed Full Text

18. Dos Santos F, Andrade PZ, Boura JS, Abecasis MM, da Silva CL and Cabral
JM. Ex vivo expansion of human mesenchymal stem cells: a more effective cell proliferation kinetics and metabolism under hypoxia. J Cell Physiol. 2010; 223:27-35. | Article | PubMed

19. Krinner A, Zscharnack M, Bader A, Drasdo D and Galle J. Impact of oxygen environment on mesenchymal stem cell expansion and chondrogenic differentiation. Cell Prolif. 2009; 42:471-84. | Article | PubMed

20. Zscharnack M, Poesel C, Galle J and Bader A. Low oxygen expansion improves subsequent chondrogenesis of ovine bone-marrow-derived mesenchymal stem cells in collagen type I hydrogel. Cells Tissues Organs. 2009; 190:81-93. | Article | PubMed

21. Chung HM, Won $\mathrm{CH}$ and Sung JH. Responses of adipose-derived stem cells during hypoxia: enhanced skin-regenerative potential. Expert Opin Biol Ther. 2009; 9:1499-508. | Article | PubMed

22. Hung SC, Pochampally RR, Hsu SC, Sanchez C, Chen SC, Spees J and Prockop DJ. Short-term exposure of multipotent stromal cells to low oxygen increases their expression of CX3CR1 and CXCR4 and their engraftment in vivo. PLoS One. 2007; 2:e416. | Article | PubMed Abstract | PubMed Full Text

23. Volkmer E, Kallukalam BC, Maertz J, Otto S, Drosse I, Polzer H, Bocker W, Stengele M, Docheva D, Mutschler W and Schieker M. Hypoxic preconditioning of human mesenchymal stem cells overcomes hypoxiainduced inhibition of osteogenic differentiation. Tissue Eng Part A. 2010; 16:153-64. | Article | PubMed

24. Haney CR, Buehler PW and Gulati A. Purification and chemical modifications of hemoglobin in developing hemoglobin based oxygen carriers. Adv Drug Deliv Rev. 2000; 40:153-69. | Article | PubMed

25. Harrison BS, Eberli D, Lee SJ, Atala A and Yoo JJ. Oxygen producing biomaterials for tissue regeneration. Biomaterials. 2007; 28:4628-34. | Article | PubMed

26. Oh SH, Ward CL, Atala A, Yoo JJ and Harrison BS. Oxygen generating scaffolds for enhancing engineered tissue survival. Biomaterials. 2009; 30:757-62. | Article | PubMed

27. Pedraza E, Coronel MM, Fraker CA, Ricordi $\mathrm{C}$ and Stabler CL. Preventing hypoxia-induced cell death in beta cells and islets via hydrolytically activated, oxygen-generating biomaterials. Proc Natl Acad Sci U S A. 2012; 109:4245-50. | Article | PubMed Abstract | PubMed Full Text

28. Bidula J, Boehm C, Powell K, Barsoum W, Nakamoto C, Mascha E and Muschler GF. Osteogenic progenitors in bone marrow aspirates from smokers and nonsmokers. Clin Orthop Relat Res. 2006; 442:252-9. I Article | PubMed

29. McLain RF, Boehm CA, Rufo-Smith C and Muschler GF. Transpedicular aspiration of osteoprogenitor cells from the vertebral body: progenitor cell concentrations affected by serial aspiration. Spine J. 2009; 9:9951002. | Article | PubMed

30. McLain RF, Fleming JE, Boehm CA and Muschler GF. Aspiration of osteoprogenitor cells for augmenting spinal fusion: comparison of progenitor cell concentrations from the vertebral body and iliac crest. J Bone Joint Surg Am. 2005; 87:2655-61. | Article | PubMed Abstract | PubMed Full Text

31. Muschler GF, Nitto H, Boehm CA and Easley KA. Age- and gender-related changes in the cellularity of human bone marrow and the prevalence of osteoblastic progenitors. J Orthop Res. 2001; 19:117-25. | Article | PubMed

32. Fehrer $C$, Brunauer $R$, Laschober $G$, Unterluggauer $H$, Reitinger $S$, Kloss $F$, Gully C, Gassner R, Lepperdinger G: Reduced oxygen tension attenuates differentiation capacity of human mesenchymal stem cells and prolongs their lifespan. Aging Cell 2007, 6:745-57. | Article | PubMed

Citation:

Heylman CM, Caralla TN, Boehm CA, Patterson TE and Muschler GF. Slowing the onset of hypoxia increases colony forming efficiency of connective tissue progenitor cells in vitro. J Regen Med Tissue Eng. 2013; 2:7. http://dx.doi.org/10.7243/2050-1218-2-7 